\title{
Referéndum del TLC en retrospectiva: Miedo, exclusión y ocultamiento desde los medios en el contexto neoliberal
}

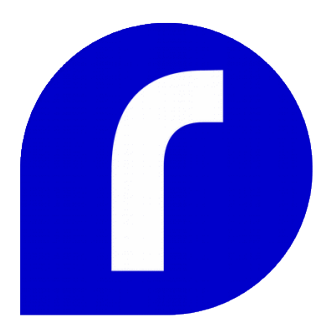

Recibido: 23 de abril 2018 Revisado: 19 de junio 2018 Aprobado: 25 de julio 2018

Marvin Amador Guzmán Costarricense. Comunicador y periodista, Máster en Tecnología Educativa. Investigador del Centro de Investigación en Comunicación (CICOM) y docente de la Escuela de Ciencias de la Comunicación Colectiva de la Universidad de Costa Rica. Ha sido docente de la Maestría en Comunicación y Desarrollo de esa misma universidad y ha coordinado diversos proyectos de Acción Social sobre comunicación y desarrollo. Actualmente es miembro de la Red de Medios e Iniciativas de Comunicación Alternativa

(Red Mica) y coordina un proyecto de investigación y un proyecto de Trabajo Comunal Universitario en el cual estudia y aplica estrategias de comunicación para el desarrollo y el cambio social.

Correo electrónico: marvin.amador@gmail.com
Resumen: Se aprovecha el aniversario del referéndum por el TLC en Costa Rica para aportar, mediante evidencias y elementos de análisis, al debate sobre los vínculos entre los medios y las élites que impulsan el modelo neoliberal, los cuales se reflejan en la existencia de un modelo mediático privado que es ideológica, política y económicamente excluyente. A partir de la identificación de varios recursos de manipulación mediática, se analizan hechos del referéndum y casos del pasado reciente que muestran la prevalencia de esos vínculos. Se pretende llamar la atención sobre la necesidad de romper la privatización "de facto" del espectro radioeléctrico y promover la apertura de medios ciudadanos y comunitarios, con el fin de fortalecer la democracia en el país.

Palabras clave: Referéndum; TLC-Costa Rica; comunicación y poder; medios comunitarios; manipulación mediática

\section{CAFTA Referendum in Retrospective: Fear, Exclusion and Concealment from the Media in the Neoliberal Context}

\begin{abstract}
The anniversary of the referendum for the CAFTA in Costa Rica is used to contribute, through evidence and elements of analysis, to the debate about links between the media and the elites that drive the neoliberal model, which are reflected in the existence of a private media model that is excluding ideologically, politically and economically. From the identification of resources of media manipulation such as fear, concealment and exclusion, some of the facts of the referendum are analyzed, as well as several cases from the recent past that show the prevalence of those links. The aim is to draw attention to the need to break the "de facto" privatization of the radio spectrum and promote the opening of citizen and community media, in order to strengthen democracy in the country.
\end{abstract}

Key words: Referendum; CAFTA-Costa Rica; communication and power; community media; media manipulation 


\section{Introducción}

En el mes de octubre se cumple un aniversario más del "referéndum" convocado por el Tribunal Supremo de Elecciones de Costa Rica (TSE) para decidir si se ratificaba o no en el país el Tratado de Libre Comercio entre Centroamérica, República Dominicana y Estados Unidos (en adelante "TLC"). Este aniversario constituye una ocasión oportuna para aportar a un urgente debate nacional sobre el papel de los medios en las dinámicas políticas y del poder, el cual es fundamental para la sociedad costarricense de inicios del Siglo XXI, caracterizada por significativas variantes en las formas de participación político-electoral, y en un contexto en el que el país se encuentra a las puertas de concretar el cambio a la "Televisión Digital" (el cambio de la tecnología analógica de transmisión y recepción de la señal de Tv a la tecnología digital), previsto para agosto del 2019, con las implicaciones sociales y políticas que comporta.

Este debate debe orientarse por el interés de concretar vías para lograr una verdadera democratización de la comunicación, así como un acceso ciudadano real a los medios, en un contexto nacional en el que, como se verá, impera un modelo mediático casi exclusivamente privado-comercial, en ausencia de medios ciudadanos o comunitarios, orientado por fines de lucro y por lógicas ideológicas conservadoras y excluyentes de perspectivas alternativas o "contestarías".

El documento apunta a atender una intencionalidad central, la de poner en evidencia que el desempeño mediático y el recurso al "miedo" —oficializado por la vía del llamado "memorándum del miedo", durante el proceso de referéndum por el TLC, no constituyeron situaciones exclusivas de aquella coyuntura, ya que los medios, en su condición de empresas privadas cuyos propietarios suelen estar vinculados a otras actividades empresariales, cumplen un rol informativo activo y permanente, convenientemente sesgado, en favor de las visiones e intereses de sus dueños. Para esto, aplican diversos recursos o estrategias de manipulación o manejo mediático que les permiten orientar la opinión de acuerdo con los intereses y perspectivas de sus propietarios, mientras se presentan ante la sociedad como entidades imparciales y objetivas. A la par de esta pretensión, se espera sensibilizar sobre la necesidad de promover un cambio normativo que asegure el acceso ciudadano a los medios, así como la apertura de medios comunitarios y ciudadanos que propicien la presencia de criterios informativos alternativos a los criterios empresariales-comerciales predominantes.

Corresponde hacer dos aclaraciones sobre el carácter del documento y sobre la metodología utilizada. Primero, el trabajo no es el resultado de una investigación formalmente sistematizada, pero ha implicado un esfuerzo de verificación y contraste de información y de hechos, basado en una revisión docu- 
mental y en el cotejo de publicaciones de diferentes medios, accesibles desde sus plataformas en internet. Segundo, no se trata de un análisis "neutral", en el sentido epistemológico-metodológico "positivista" tradicional. Además de que cuestionamos tal vía de acercamiento al conocimiento, el análisis y la reflexión se plantean desde la perspectiva de un actor ex-activista del "No" que, a la luz de algunas de las herramientas conceptuales del Paradigma Crítico de la Comunicación y de la perspectiva latinoamericana de la "Comunicación Participativa para el Desarrollo", integra elementos de la experiencia vivida, diversos insumos testimoniales sobre lo ocurrido en el referéndum -recopilados en el marco del trabajo realizado en su momento por la "Asociación de Iniciativas Populares Ditsö"1_- así como vivencias y estudios propios y colectivos realizados tanto desde la docencia universitaria como desde la Red de Medios e Iniciativas de Comunicación Alternativa (Red Mica) sobre la realidad mediática actual.

Con el fin de abonar a un análisis "más allá" del memorándum y del referéndum, dedicaremos las próximas páginas a proponer un marco analítico pertinente, así como a describir algunas evidencias, correspondientes tanto a lo ocurrido durante el referéndum como al escenario del pasado reciente del acontecer nacional.

\section{Comprendiendo los vínculos: los medios como instrumentos de reproducción simbólica}

1. Ditsö" es una asociación sin fines de lucro que hace acompañamiento a organizaciones de base. Durante y después del referéndum, facilitó un trabajo de registro audiovisual de hechos y testimonios que evidenciaron diversas manipulaciones cometidas por los medios y por autoridades del gobierno, así como formas de "extorsión" laboral cometidas por empresarios en todo el país. El material producido fue secuestrado en una etapa avanzada de

redacción de un guion y de allí derivó la producción denominada "Santo Fraude".

El abordaje crítico de la comunicación nos permite entender que los seres humanos somos seres "simbólicos", en tanto nuestros vínculos con los demás y, en general, con el mundo que nos rodea, se establecen gracias a la capacidad de atribución de sentido o significado que empezamos a forjar desde que estamos en el vientre materno. Este andamiaje simbólico-significante se construye en el vínculo permanente con los elementos del entorno, el cual se da dentro de un contexto histórico social-cultural concreto, y nos lleva a constituimos en seres sociales, tal y como lo plantea Fuentes (2015, 209): "...la actividad comunicativa cumple la función de consolidar y reproducir una visión de la realidad conjunta para los miembros de una sociedad, a partir de múltiples recursos tecnológicos y discursivos, coadyuvantes de la función explicativa de la vida social para los sujetos".

Comprender este carácter simbólico consustancial al ser humano es fundamental para entender, a su vez, el importantísimo influjo de los medios en nuestras sociedades. Si bien crecemos en un sistema diverso y complejo, donde múltiples núcleos colectivos e instituciones sociales se implican a lo largo de nuestras vidas en el proceso de construcción de sentido — por ejemplo, la familia, la Escuela, la Religión y las instituciones relacionadas al sistema de producción- (Guinsberg 1988, 14), hoy día los medios juegan un papel esencial dentro de ese sistema.

Desde que pasaron a ser "la vitrina" para el conocimiento de todo cuanto ocurre más allá de nuestra percepción, y conforme las relaciones de los indi- 
2. Proponemos esta categoría, como término simplificador, dado que aglutina a los actores vinculados a lo que Robles y Voorend definen como "los nuevos grupos de poder costarricenses", en el que incluyen al sector financiero inmobiliario y turístico, así como a otros que han pasado a la gestión de compra-venta de empresas y a procesos de "gerentización", donde a veces pierden la propiedad, pero no el control de la empresa o negocio. viduos y colectivos humanos se fueron ampliando hasta alcanzar horizontes globales, inalcanzables a las posibilidades de la percepción directa, los medios se constituyeron en instrumentos modeladores determinantes de la atribución de significado de todo lo que ocurre más allá de nuestros "ojos". Así, en los términos de Valderrama $(2005,57)$ : "los medios modelan la percepción del mundo y hacen partícipe a cada persona de su forma de entenderlo". Lo que los medios presentan en sus plataformas se constituye, en el devenir del proceso de desarrollo personal, en referente previo y presente (datos, informaciones, imágenes, visiones-perspectivas, opiniones, aspiraciones, etc.) para articular y atribuir significado al grueso de las circunstancias concretas de la cotidianeidad y de la realidad tanto inmediata como mediata, para las que, en general, se dispone de pocos o de ningún referente articulador alternativo. Este impacto referencial articulador se amplía en tanto exista una mayor uniformidad en la propuesta mediática.

Muy a pesar de la emergencia y crecimiento de nuevas plataformas informativas, como las redes sociales, los medios tradicionales desempeñan todavía un papel fundamental como instrumentos de reproducción simbólica, dado su peso como vías de información. En el caso de Costa Rica, según estudios del CIEP (2017), medios como la radio, la prensa escrita y, en especial, la televisión, siguen estando hoy día entre las principales vías utilizadas por la mayoría de la población para informarse. Para finales del 2016, por ejemplo, un $88,5 \%$ de la población tenía a la televisión como uno de sus principales medios de información (CIEP 2017, 27). A esto se debe agregar el hecho de que, en buena medida, mucha de la información que transita por las redes sociales es reproducción directa o indirecta de lo que informan los medios tradicionales.

La coyuntura que vivió Costa Rica para tramitar y dirimir todo lo concerniente al TLC — tanto en el período previo al referéndum como ( $\mathrm{y}$, de manera especial) durante el propio proceso en que se definió su ratificación mediante la consulta popular-, constituyó lo que sin duda ha sido el mayor laboratorio experiencial, en la historia reciente del país, para la verificación empírica de las "conexiones" político-ideológicas y la comunión de intereses entre "los medios" y los sectores vinculados a las élites del poder en el país (la clase política del bipartidismo tradicional, de tendencia neoliberal, y el sector empresarial-financiero). ${ }^{2}$

La puesta en evidencia de estas "conexiones" durante ese proceso permitió constatar el endeble andamiaje empírico del imaginario social predominante en la sociedad costarricense según el cual los medios constituyen "entidades" imparciales y neutrales que solo se encargan de mediar, de manera "objetiva", información inocua sobre hechos del acontecer. Según este imaginario social, que es predominante, los medios cumplen esta labor guiados por objetivos "neutrales" relacionados con el "interés público" (Guinsberg 1988, 18). No es así en Costa Rica, como tampoco lo es en ningún otro lugar en el que predomine un sistema de medios privados ligados al capital y a los objetivos de lucro. 
Los vínculos entre élites de poder y medios, que se pusieron en evidencia durante el referéndum, reflejaron una relación que, más que "casual" o coyuntural, tiene un carácter estructural. Los grupos que detentan el poder en cada momento histórico han estado vinculados al control de los sistemas que funcionan para la construcción-articulación del sentido. En las sociedades capitalistas, en general, los medios de difusión masiva expresan un vínculo consustancial con el capital y, desde allí, con las expresiones predominantes del poder. Hay una relación que es económica, tanto como política y jurídica. Una forma de verlo es considerar el hecho de que, para poner a funcionar un medio de impacto nacional, se requiere un importante volumen de capital que solo pocos pueden disponer para esos usos. Pero, aunque el factor económico es importante, el vínculo no se establece solo en función de esto, sino que también se concreta gracias a otros elementos estructurales, siempre ligados al poder, como, por ejemplo, la estructura jurídica. Al respecto, veremos más adelante cómo, en el caso de Costa Rica, el ejercicio del poder aplica para evitar una reforma legal que permita romper el oligopolio privado-comercial de los medios que usan el espectro radioeléctrico.

En el contexto costarricense del presente, algunos imaginarios simbólicos construidos desde los medios en virtud de manejos informativos sistemáticos sobre aspectos concretos de la realidad social, y que podrían ponerse como ejemplo de este "impacto" mediático ligado al ejercicio del poder, son, por un lado, el evidente prejuicio negativo (que a veces parece rayar en odio) contra las organizaciones sindicales, el cual se contrapone, por otro lado, a la prevalencia de un "estatus" positivo del empresariado (de dónde más, sino de los medios, puede tener referentes sobre los sindicatos el grueso de la población que no participa en esas organizaciones).

Otro ejemplo es la percepción popular sobre la corrupción, en virtud de la cual, en general, se manejan criterios negativos contra el sector público, mientras que se ignora el papel equivalente y complementario que desempeñan actores del sector privado ligados al empresariado. De igual modo, en un contexto en el que se discute una propuesta de reforma fiscal que apunta a "cargar" el peso del déficit sobre el sector asalariado, se puede señalar el hecho de que el grueso de la población reproduce el discurso mediático-empresarial según el cual el sector público es responsable del déficit fiscal, en tanto que ignora los hechos sobre la forma en que el sector privado, en especial el sector empresarial y comercial, evade o elude impuestos por una cantidad que supera con creces el mismo déficit.

En términos académicos, la discusión sobre la existencia de los vínculos entre los sectores que detentan el poder y los medios no es para nada nueva. En lo que a acercamientos relacionados con el campo de la comunicación se refiere, desde hace ya mucho tiempo se ha venido señalado y cuestionado este vínculo, en abordajes planteados desde la Sociología Crítica y la Sociología de la Comunicación, la Psicología Social, la Comunicación Política y desde diversos enfoques del Paradigma Crítico de la Comunicación, en campos como la "Economía Política de los Medios" y el enfoque latinoamericano de "la Comunicación Participativa para el Desarrollo", entre otros. 
3. Se recomiendan las obras "La Manipulación de la Información: Polonia en la prensa dominante cos tarricense", de Willi Soto Acosta, y "Cómo hacer Análisis ideológico: propuesta de método para analizar ideológicamente un discurso", de Óscar Jiménez Ardón.
Desde estos abordajes, en general, se entiende que los medios cumplen funciones como instrumentos de construcción y reproducción del consenso social, es decir, orientados a la instauración de condiciones inter-subjetivas de aceptación y reproducción del sistema. Para esto, concretan un manejo informativo en el que aplican diversos recursos simbólicos - formas de manipulación-, que se concretan en prácticas diversas, según sea el tipo de medio y las condiciones políticas de cada coyuntura: "la forma en que los medios presentan la información, primando, ocultando o silenciando, es un mecanismo del que se valen para aniquilar conceptualmente todo lo que está fuera de su universo" (Ramos 1995, 111).

Tres autores nacionales que han hecho aportes importantes relativos al análisis y comprensión de estos recursos estratégicos informativos, todos desde consideraciones para el análisis ideológico del discurso, son Jaime González, Willi Soto y Óscar Jiménez. ${ }^{3}$ Entre ellos, González (1988) propone los que denomina "fundamentos para un análisis ideológico", y considera tres mecanismos fundamentales para el cumplimiento de las funciones ideológicas del discurso: la universalización, la evasión y el mecanismo catártico. El mecanismo de universalización, o "generalización", consiste en "tratar de darle una aparente dimensión de globalidad o de generalidad a un fenómeno particular" (González 1988, 14). Con este recurso se intenta "presentar" como aplicable para la mayoría o la totalidad de la población algo que es básica o exclusivamente del interés y la conveniencia de los sectores que detentan el poder.

La evasión, por su parte, "consiste en recurrir a elementos fantasiosos para tratar de atraer la atención de las personas hacia hechos irreales" (González $1988,14)$. La importancia de este recurso no reside tanto en que apunta a inducir interés por pseudo-realidades basadas en fantasías, sino, más bien, en el hecho de que, por esta vía, apunta a evitar la atención de los aspectos relevantes o trascendentes de la realidad social. A propósito de este recurso, corresponde reconocer el enorme peso que tienen los contenidos de "entretenimiento" en las programaciones de los medios nacionales, incluso en los espacios periodísticos, lo cual contrasta de manera significativa con la ausencia casi absoluta de contenidos educativos o científicos, o con la desaparición de espacios de debate sobre temas trascendentales, en los que, de todas formas, no suele haber participación de actores que expresen voces y visiones diversas, diferentes y contrapuestas en lo sustantivo a los intereses predominantes sobre esos temas.

No es casualidad el que, pese a este peso contundente de contenidos para el "entretenimiento", desde la mal llamada "teoría" periodística funcionalista (que se ha construido en lo fundamental a partir de "reflexiones subjetivas" basadas en el ejercicio periodístico empírico), se estableció que uno de los tres objetivos del periodismo, a la par de "informar" y "educar", es "entretener". Ya hace algunos años encontrábamos que casi el $70 \%$ de los contenidos informativos de los dos principales telenoticieros nacionales (Repretel y Telenoticias) estaban relacionados con hechos o temas intrascendentes, y el grueso de esos contenidos correspondía a deportes, espectáculos y publicidad (Amador 2003). 
El tercer recurso propuesto por González es el de catarsis, el cual "consiste en crear expresiones que permiten exteriorizar la tensión psicológica creada por el sistema de una manera inofensiva para el mismo (González 1988, 15). A este recurso responden, entre otros, contenidos como los deportivos, o los que reflejan alguna forma de violencia física. En nuestra realidad mediática, este recurso suele "aparecer" de manera complementaria con el recurso de evasión. Es claro que ambos recursos estratégicos se manifestaron durante el contexto del referéndum por el TLC, aparejados al recurso del miedo, cuando el mensaje de que el TLC era necesario y conveniente para el país se reiteraba de manera sistemática a través de los informativos y de los discursos de los diferentes funcionarios públicos y empresarios vinculados a la campaña del "Sí".

Otros recursos simbólicos estratégicos que se presentan en el manejo mediático y que no son mencionados por González, pero que proponemos por su importancia en el análisis general, son el de "reiteración" y el de "desarticulación". La reiteración consiste en repetir sistemáticamente determinados contenidos, durante un período concreto y bajo enfoques o abordajes convenientes, a fin de procurar la aceptación, el aval o apoyo y la "normalización" de aquello que se expresa en los mensajes que se transmiten. La desarticulación, por su parte, consiste en presentar los hechos noticiosos de manera aislada o desvinculada entre sí y/o de los aspectos estructurales que los explican o que constituyen sus causas fundamentales. En virtud de este recurso, las personas "construyen" una realidad fragmentada y carente de jerarquías, de modo que todo resulta igual de importante o irrelevante, dado que no se cuenta con criterios para determinan cuán fundamental puede ser, para el individuo o la colectividad, una situación o hecho determinado en una coyuntura concreta.

En este trabajo nos concentraremos en tres recursos mediáticos, que son, a nuestro juicio, los que revisten mayor importancia relativa debido a que tienen un mayor "peso" significativo desde la perspectiva política, dadas las implicaciones que tienen en cuanto a la restricción de información y de participación ciudadana en los procesos de toma de decisiones.

En primer término, está el "recurso al miedo", del cual el memorándum fue evidencia tangible, y con el que se apela, a partir de fundamentos que suelen ser falaces y carentes de sustento, a mover "emociones" para apelar a no hacer o hacer algo por temor a consecuencias ficticias o especulativas. En segundo término, proponemos el recurso del "ocultamiento", el cual, tal y como lo sugiere Ramos $(1995,111)$, consiste en ignorar y en evitar hacer visible o del conocimiento público aquello que no conviene o que expresa algún tipo de oposición o negación de los intereses propios. A propósito de este recurso, Guinsberg $(1988,16)$ plantea que "el grado en que los medios de comunicación tienen influencia en su audiencia depende no solo de lo que se dice, sino, aún más significativamente, de lo que no se dice. Porque estos medios no solo siguen afirmando el "statu quo", sino, en la misma medida (sic), no estimulan interrogantes esenciales acerca de la estructura de la sociedad". 
Por último, proponemos el recurso de la "exclusión", que consiste en negar o impedir espacio a actores (colectivos o individuales) que plantean ideas 0 propuestas alternativas o contestatarias a los intereses y propuestas de quienes detentan el poder. La exclusión implica un "nivel" más allá del ocultamiento, pues, mientras este implica una "simple" acción de "omisión" (se minimiza o no se informa del todo sobre un hecho o una versión alternativa), la exclusión constituye un recurso de negación expresa del espacio a actores concretos que manifiestan interés de dar a conocer sus visiones o posiciones.

La aplicación de estos recursos estratégicos ha sido "norma" en el actuar mediático costarricense a lo largo de todo el período de imposición-instauración de las políticas neoliberales. Si bien su uso fue sistemático durante el proceso del referéndum, su aplicación sigue siendo habitual en los informativos de los grandes medios de difusión en el país, con mayor o menor peso según lo demanden los "intereses afectados" y según las circunstancias político-económicas.

\section{El modelo privado-empresarial de medios y la privatización de hecho del sistema mediático}

Aunque las "conexiones" entre medios y élites de poder son propias de cualquier sistema de medios en las sociedades capitalistas, también es cierto que en nuestro país expresan una forma notoria, debido al impacto y a la permanencia en el tiempo de un modelo que, como se verá, es casi exclusivamente privado y comercial, y que carece —no por casualidad- de medios de carácter comunitario.

El sistema de medios de difusión que predomina en Costa Rica es fundamentalmente privado. Tanto la gran prensa escrita como la mayoría de los medios de radio y televisión existentes son empresas privadas que tienen como fin primario el lucro, y sus noticieros o informativos son parte de las propuestas de contenido y de las dinámicas comerciales que les son propias. A diferencia de lo que ocurre en el escenario mediático en otros países, sobre todo en radio y televisión, no existen medios comunitarios independientes que trabajen en función de objetivos informativos de interés social no ligados al interés de lucro, y los escasos medios públicos existentes (el sistema de medios de la UCR y el SINART) trabajan con recursos limitados y tienen poco alcance. La estructura de propiedad que caracteriza este sistema en el país muestra una clara concentración de medios privados, y de parte de determinados grupos en particular.

Los dueños o accionistas de la mayoría de medios en el país suelen ser, a su vez, empresarios con intereses en otras actividades productivas o financieras (véase Jiménez 2017). Los propietarios de los medios más grandes y de mayor alcance, como La Nación, Canal 7 o Repretel, forman parte del sector 
más adinerado del país. En el caso de Repretel, que en realidad constituye una cadena que acapara 15 concesiones de televisión (aunque mantiene solo 4 activas), así como 9 concesiones de radio (Jiménez 2017, 55-56), su dueño, el guatemalteco Ángel González, es un magnate que posee medios en casi toda América Latina.

Desde estas plataformas mediáticas privadas se tiende a generar una especie de "pensamiento" único, que refleja los intereses económicos-comerciales del empresariado y las perspectivas político-ideológicas liberales-conservadoras que, en lo fundamental, les son afines. Tal como lo afirma Jiménez $(2017,50)$, "se evidencia en Costa Rica un sistema de medios eminentemente liberal, que implica un desarrollo audiovisual basado en los movimientos del mercado".

En el caso de la prensa escrita, los medios periodísticos privados de alcance nacional y de base empresarial en el país son prácticamente todos. En cuanto a la radio y la televisión abierta, que son los medios que utilizan el "espectro radioeléctrico" —un recurso público, patrimonio de toda la ciudadanía, y que constituye el soporte por el cual se difunden las ondas que transportan las señales-, los medios privados son, también, casi que todos: 93\% en radio AM (54 medios); $87 \%$ en radio FM (50 medios) y 95\% de todas las televisoras de "Tv Abierta" (89 medios) (Jiménez 2017, 50 y PROLEDI 2018). Si separamos los medios religiosos - que son medios privados- de los medios empresariales-comerciales, tenemos que estos últimos representan el $74 \%$ en radio $\mathrm{AM}$, el $83 \%$ en radio $\mathrm{FM}$ y el $77 \%$ en televisión abierta (Jiménez, 2017 , p. 50). Los medios religiosos coinciden con los comerciales no solo en el interés por los recursos económicos (ya que dedican grandes esfuerzos a captar dineros, a modo de donaciones, de los cuales existe escasa o nula información sobre procedencia y uso), sino también en sus estructuras de propiedad y en la ausencia de contenidos educativos y de propuestas alternativas y contestatarias.

También existen medios públicos en Costa Rica. Constituyen una minoría en relación con los medios privados comerciales y religiosos. Según Jiménez (2017, p. 50) y PROLEDI (2018), los pocos medios públicos existentes son los del Sistema Nacional de Radio y Televisión (SINART) y los de la Universidad de Costa Rica (UCR). En radio AM, estos medios constituyen el 7\%, en FM son el 9\%, y en Televisión Abierta son el 5\%.

El panorama de predominio de medios privados en el uso y aprovechamiento del espectro radioeléctrico en el país se muestra más crítico cuando se confirma una clara condición de acaparamiento de frecuencias por parte de algunas empresas o grupos concretos. Por ejemplo, en radio, el Grupo Columbia tiene 7 frecuencias en AM y 5 en FM (12\% y 9\% del espectro, respectivamente; $11 \%$ del total en radio); Repretel tiene 4 frecuencias en AM y 7 en FM (7\% y $13 \%$, respectivamente, $10 \%$ del total en radio); la Conferencia Episcopal tiene 7 frecuencias en AM y 3 en FM (7\% y 13\% del espectro, respectivamente; $9 \%$ del total en radio); la Cadena Radial Costarricense tiene 1 frecuencia en $\mathrm{AM}$ y 5 en $\mathrm{FM}$ ( $2 \%$ y $9 \%$, respectivamente; $5 \%$ del total en radio); y el Grupo Nación tiene 3 frecuencias en AM (5\% de AM; $3 \%$ del total en radio) 
(Jiménez 2017, 56). En total, en manos de estos 6 grupos empresariales hay 41 frecuencias del total del espectro dedicado a la radio.

Por otra parte, en televisión abierta, el Grupo Repretel tiene 15 concesiones (21\% del total), la cadena religiosa Enlace TBN tiene 8 concesiones ( $11 \% \mathrm{del}$ total), Televisora de Costa Rica (Canal 7) tiene 5 concesiones ( $7 \%$ del total), Teleplus tiene 6 concesiones ( $8 \%$ del total), la Conferencia Episcopal tiene 3 concesiones ( $4 \%$ del total) y Grupo Extra tiene 2 concesiones ( $2 \%$ del total) (Jiménez 2017, 56). En total, en manos de estos 7 grupos empresariales está el 55\% del total del espectro dedicado a la Tv abierta.

Como se podrá notar, los actores que acaparan concesiones en radio se repiten significativamente respecto de los que acaparan en televisión abierta, mientras que no existen medios comunitarios o ciudadanos en el país. La figura de medios comunitarios ni siquiera está contemplada en la normativa vigente, de modo que somos uno de los pocos países de América Latina en que la ley no reconoce ese tipo de medios y en que no existen concesiones para emisoras comunitarias (OBSERVACOM 20017, 4).

Una única organización sin fines de lucro cuenta con concesiones de radio en el país: es el "Instituto Costarricense de Enseñanza Radiofónica" (ICER), una "ONG" que dispone de dos frecuencias en AM y una en FM (Jiménez 2017,51 ). Pero estos usos no corresponden a medios comunitarios. Primero, porque, aunque maneja una red de 15 pequeñas emisoras ubicadas en la periferia del Valle Central, el ICER no es emisor. Lo que hace es "autorizar" el uso de esas frecuencias a colectivos de personas que administran las emisoras con fines que se suponen educativos y culturales. En segundo término, estas emisoras no tienen independencia plena, ya que están supeditadas a condiciones, recursos, apoyos y decisiones del ICER. El estatuto que rige la relación entre estos colectivos y el ICER fue elaborado de manera unilateral por esa ONG, y limita las posibilidades de los grupos a constituirse en organizaciones formales. Incluso, se les supedita doctrinariamente a lo que el ICER establezca (ICER s.f.).

El que el país presente este modelo casi exclusivamente privado -empresarial-comercial- en la radio y la televisión, con una mínima participación de medios públicos y una ausencia total de medios comunitarios sin fines de lucro, implica una forma de privatización "de facto" del espectro radioeléctrico, a pesar de que constituye un recurso público (un bien "demanial"), que se supone es propiedad de la nación y, por ende, de la ciudadanía.

\section{Refrescando la memoria: el modelo neoliberal, la gestación del TLC y el camino al referéndum}

Dentro del proceso de implementación de las políticas neoliberales en la sociedad costarricense, iniciado en los años 80, el TLC con Estados Unidos se presentó como una aspiración "principal" para el sector empresarial-financie- 
ro. Costa Rica había emprendido el proceso de reforma basado en lo que se conocería como el "Consenso de "Washington", para romper con el modelo social-demócrata y del "Estado de Bienestar", de la mano de los gobiernos del bipartidismo - el PUSC y el PLN- que se turnaban la gestión sin mayores diferencias ideológicas de fondo. Este proceso se imponía sin ningún tipo de espacio para el disenso o el debate público.

En principio, la puesta en vigencia del TLC permitiría concretar algunos de los grandes pendientes del proceso, y entre ellos estaba profundizar la vinculación con el mercado internacional a partir de esquemas de "libre" comercio y la apertura y/o privatización del sector de telecomunicaciones. Sin embargo, desde sus inicios, el proceso de implementación de reformas neoliberales había generado tensiones y resistencias. Ya en 1999 se había producido el movimiento de oposición al "Combo del ICE", gracias al cual se revirtió una espuria ley con la que se pretendía concretar la apertura del sector de telecomunicaciones.

Tal y como lo plantea Raventós $(2008,16)$, "desde el 2003 el TLC se había ido convirtiendo gradualmente en el principal tema de debate público y de diferencia política". Aunque el malestar por de parte del movimiento social venía haciéndose manifiesto desde antes de que se iniciaran las negociaciones, y en particular durante las negociaciones mismas, la oposición y una progresiva polarización social se fue consolidando a partir de la llegada de Arias al gobierno, y del subsecuente envío del tratado a la Asamblea. Arias afirmó que, al tener al TLC como una de sus promesas de campaña, el triunfo obtenido en las elecciones del 2006 lo legitimaba para dar trámite a su aprobación. Sin embargo, los sectores opositores desconocían tal legitimidad debido a que el triunfo de Arias se dio por un estrechísimo margen de solo poco más de un punto porcentual (Arias había obtenido $42,26 \%$ de los votos, contra un 41,11\% de Ottón Solís, del PAC).

En este clima de polarización creciente, sin que se diera ninguna discusión amplia al respecto dentro del movimiento social, el 12 de abril del 2007 el exdiputado y excandidato del PLN José Miguel Corrales, un manifiesto opositor al Tratado, a título personal y apoyado por un pequeño grupo de simpatizantes, presentó una solicitud ante el Tribunal Supremo de Elecciones (TSE) para recoger 150 mil firmas, con el fin de presentar la iniciativa ciudadana para la convocatoria a un referéndum que dirimiera la ratificación del TLC. Aunque la idea de una consulta popular había sido planteada de manera informal por diversos actores, en general, dentro del movimiento social se tenía la impresión de que esa apuesta era demasiado arriesgada, dada la desarticulación y la enorme asimetría de recursos y el alto nivel de desinformación que había en la población.

"El TSE acogió la solicitud, lo que implicó un giro en el proceso, y el consecuente abandono por parte del gobierno de la vía parlamentaria para la ratificación del CAFTA" (Vargas 2008, 151). Un día después, el 13 de abril, el Presidente Arias anunció la decisión de someter a la Asamblea Legislativa un decreto en el que solicitaba la convocatoria al referéndum para definir la posible ratificación de TLC. Esta re-acción se adoptaba como una forma de acelerar 
el proceso ante la iniciativa de Corrales, debido al riesgo de que, de recogerse las firmas —algo que era bastante posible — el TLC no se pudiera aprobar antes del plazo: "como la iniciativa ciudadana implica un proceso no menor a 15 meses entre la recolección de firmas, verificación, convocatoria y realización de la consulta, el referéndum se realizaría fuera del plazo que el país tenía para ratificar el tratado según el texto del CAFTA, que vencía el 29 de febrero de 2008 (Vargas 2008, 151). El 23 de abril del 2007, la Asamblea Legislativa avaló el decreto presentado por Arias, y así se facultó la organización del referéndum. Finalmente, el jueves 12 de julio, el TSE formalizó la convocatoria.

El referéndum acrecentó la polarización social. El proceso de votación ponía de un lado a los movimientos sociales, que se unieron en el denominado "Movimiento del No", y del otro lado estaba la denominada "Alianza por el Sí", que reunía al grueso del sector empresarial-financiero, al gobierno, los partidos políticos del bipartidismo tradicional (el PUSC y el PLN, al que se sumaba el Partido Libertario) y, de manera "solapada", a los grandes medios de difusión.

Al Movimiento del "No" lo integraba un amplio conglomerado de organizaciones sociales sin fines de lucro. Aglutinaba trabajadores organizados, sectores ecologistas, pequeños productores, campesinos, comunidades organizadas e incluso el grueso del sector académico y estudiantil de las universidades públicas. Desde acá se cuestionaba la manera en que las élites venían imponiendo medidas neoliberales inconsultas para transformar el modelo social y la institucionalidad solidaria construida desde el Estado Social de Bienestar, a fin de imponer una institucionalidad basada en la lógica del libre mercado. Al TLC se le cuestionaba por ser parte de esa propuesta y por considerársele espurio, dada la forma secreta en que se negoció y dada la exclusión de representantes del movimiento social en dicha negociación. Se cuestionaban las asimetrías tecnológicas, productivas y de recursos del país con Estados Unidos, así como el hecho de que implicaba la continuidad de los fallidos proyectos de apertura y privatización de instituciones públicas, incluyendo al ICE, entre otros argumentos.

La "Alianza por el Sí" manejaba un discurso centrado en el supuesto imperativo de "engancharse" a la globalización y al mercado libre para no dejar al país rezagado y pobre, al que se sumaban ideas sobre empleo y riqueza abundantes que generaría el TLC para todos. A este discurso se sumaba el argumento de que los que se oponían al TLC lo hacían por razones ideológicas, mientras que los que lo apoyaban se fundamentan en criterios técnicos y en leyes económicas. En su propia esencia, el discurso del "Sí" comportaba el mensaje del "miedo" a un futuro sin TLC, el cual se incrementó conforme pasó el tiempo y las simpatías por el "No" fueron creciendo. Los mensajes concretos de este "bando" incorporaron diversas formas ligadas a estas ideas. A modo de ejemplo, veamos algunas frases dichas por el propio presidente Arias en las tantas giras "de trabajo" que realizó mientras hacía proselitismo a favor del TLC y prometía obras y regalos a cambio de apoyo todo 
esto en el ejercicio de sus funciones, dado el aval que le diera el TSE (Ditsö y otros, 2009):

- "El tren solo pasa por la estación una vez".

- El TLC no nos va a hacer ni más buenos ni más malos, no nos va a hacer ni más rubios ni más morenos, simplemente nos va a hacer más ricos o más pobres, nada más".

- “¿A dónde van a trabajar estos chiquitos cuando sean profesionales o salgan del colegio?

- "O tenemos un TLC con EU, o les exportamos gente".

- "Aislarnos del comercio libre con el resto del mundo es la mejor receta para hacernos más pobres".

- "Los ricos no necesitan del gobierno, los ricos no necesitan del TLC, óigase bien. Mienten los señores del No cuando dicen que el TLC solo favorece a los ricos, eso es falso, porque los ricos con TLC o sin TLC ya son ricos".

- "El TLC les va a ayudar a ustedes, que es la gente humilde de este país".

- "Si no pasa el TLC, esto será un suicidio colectivo para Costa Rica".

En el medio de estos dos grandes bloques del "Sí" y del "No" permanecía una gran parte de la población, que se mostraba escéptica y cargada de dudas, con grandes carencias de información, y con poco conocimiento para poder decidir con criterio informado. Con este panorama, lo que se venía apuntaba a constituirse en una lucha entre David y Goliat. Pero, aunque al final de cuentas el resultado confirmó que quienes manejan "las cuerdas" del poder sacarían ventaja, lo cierto es que esta "victoria" obligó a esas élites a poner sobre la mesa una buena parte de su "arsenal", a costa incluso de poner en riesgo la institucionalidad y legitimidad democrática del país.

\section{Los medios y el poder durante el referéndum}

Si bien el referéndum por el TLC implicó mucho más que meros aspectos comunicacionales y mediáticos, el hecho de que fuera una figura que se concretaba por la vía de un proceso de votación le confiere un carácter simbólico-comunicacional particular. En este sentido, el proceso fue, en sí mismo, una clara evidencia de la forma en que operan los procesos comunicacionales y simbólicos para el ejercicio del poder.

Cortés $(2009,65)$, en un balance hecho desde la perspectiva de la Comunicación Política, hace un análisis del referéndum para el que propone ocho ejes analíticos. Con la idea de depurar nuestro análisis, utilizaremos como re- 
ferencia los siete primeros ejes propuestos por Cortés y algunas de sus principales ideas, y agregaremos uno adicional, correspondiente al papel desempeñado por el TSE durante el proceso, dada la adopción de decisiones que apuntaban a beneficiar al "Sí".

\section{Financiamiento de las partes en el referendo y la negativa del "Sí" a informar las fuentes}

El balance en los recursos disponibles por parte de los "bandos" participantes en el referéndum fue absolutamente desigual. Mientras que el "Sí" contaba con el apoyo financiero del gran capital nacional y transnacional (Cortés $2009,65)$, el cual se materializó en una abundante pauta publicitaria y de propaganda, el Movimiento del "No" solo disponía de los limitados aportes en recursos personales, financieros y materiales de las organizaciones y personas que lo conformaban. Aunque los resultados ajustados del referéndum mostraron que las estrategias aplicadas por el "No" lograron superaron con creces ese balance inicial, lo cierto es que la diferencia en los recursos invertidos fue sustantiva. Durante los poco más de tres meses que duró la campaña previa al referéndum, el "Sí" invirtió 888 millones de colones en gastos de publicidad, frente a 116 millones del NO.

El origen de estos recursos no se aclaró nunca. La "Alianza por el Sí" se negó a revelar el origen de esos dineros, con lo cual violó la legislación nacional. Las dudas sobre el origen del financiamiento no solo eran meritorias debido a esta falta de transparencia, sino también en virtud de que, años antes, se había hecho público el hecho de que el equipo negociador del TLC había recibido financiamiento directo del gobierno de Estados Unidos, a través de recursos canalizados por la Fundación Costa Rica - Estados Unidos (véase Ducca 2017).

\section{La participación del Ejecutivo}

En lo que constituyó evidencia de una clara "inclinación" de parte del TSE hacia la Alianza por el "Sí", mediante la resolución No 1119-E-2007 (TSE 2007) esta institución avaló que el Presidente de la República y las autoridades del Poder Ejecutivo hicieran proselitismo. Este aval no solo permitió a los funcionarios del Ejecutivo incorporar el discurso del "Sí" en sus agendas de trabajo, sino que condujo a un uso sistemático de recursos públicos para favorecer a esa agrupación, y llevó a la materialización de una campaña de "chantajes" proselitistas, al mejor estilo de las campañas populistas del bipartidismo, desde la cual llovieron promesas de parte del gobierno a cambio del apoyo popular al Sí.

Así, en las mismas actividades en que se entregaban bonos y ayudas de diversos programas sociales, los diferentes funcionarios del gobierno hacían proselitismo a favor del TLC y prometían obras y ayudas a cambio de apoyo. 
A continuación se detallan algunas de las promesas de Arias en sus visitas a comunidades, de acuerdo con el registro audiovisual y los testimonios recopilados por Ditsö y otros (2009):

- "En el puro centro de Desamparados vamos a construir un parque industrial de 240 hectáreas".

- "Aquellos que hoy vienen a trabajar en bicicleta van a poder venir en una motocicleta BMW, y los que vienen en una motocicleta BMW van a poder venir en un Hyundai, y los que vienen en un Hyundai posiblemente van a poder venir en un Mercedes Benz".

- “También me están pidiendo la construcción de un gimnasio multiuso para el Liceo Mauricio Alvarado Vargas y eso sí le puedo decir que se lo vamos a construir".

- "Bueno, hoy venimos a sellar un pacto. Entonces, ustedes nos apoyan con el TLC y nosotros les construimos un gran aeropuerto (dicho en Palmar Sur).

Hay que señalar que ninguna de estas y de otras muchas promesas ofrecidas se cumplió.

\section{La campaña del miedo por parte del "Sí" y el memorándum Casas-Sánchez}

La campaña del "Sí", expresada en los contenidos informativos de los medios, en las actividades y discursos del Presidente Arias y de los miembros del gabinete de gobierno, así como en las comunicaciones a los trabajadores de parte de los patronos de la gran mayoría de las empresas, estuvo centrada en una constante amenaza ante las supuestas consecuencias negativas para el empleo y el rumbo del país que tendría la no ratificación del TLC. EI recurso al miedo también incluyó difamaciones constantes para el Movimiento del "No", a quienes se vinculaba, sin fundamentos, con el gobierno de Hugo Chávez, con Cuba y con proyectos comunistas. Incluso se llegó a afirmar públicamente, sin ninguna fundamentación, que este movimiento recibía recursos económicos del gobierno venezolano.

El 7 de setiembre, a solo un mes de que se realizara el referéndum, el Semanario Universidad publicó los alcances del que luego sería conocido como "El Memorándum del Miedo". Se trataba de una comunicación formal, remitida al Presidente Arias el 29 de julio por parte de Kevin Casas, Vice-Presidente de la República, y Fernando Sánchez, diputado del PLN. En este documento, además de hacerse un análisis de la situación de la campaña del "Sí", Casas y Sánchez sugerían, entre otras estrategias, impulsar una fuerte campaña mediática y de parte de los patronos que se sustentaba en el discurso del miedo (Casas y Sánchez 2007): 
Este miedo es de 4 tipos:

I. Miedo a la pérdida de empleo.

II. Miedo al ataque a las instituciones democráticas.

III. Miedo a la injerencia extranjera en el No (hay que restregar por todas partes la conexión del No con Fidel, Chávez y Ortega).

IV. Miedo al efecto de un triunfo del No sobre el Gobierno.

"No hay que tener pudor en saturar los medios". Hay que "Sembrar cizaña", señalaba el memorándum. Adicionalmente, abogaba para que, asegurando medidas que permitieran "cubrirse las espaldas ante el TSE", se comprometiera a los alcaldes para meterse en la campaña: "El alcalde que no gana no va a recibir ni un cinco en los próximos tres años. El que no se mete de lleno, se quema". También sugería asociar al "No" con actos de violencia: "Es crucial convertir al No en equivalente de violencia" (véase Casas y Sánchez 2007).

Desde Casa Presidencial y la bancada de diputados del PLN se intentó deslegitimar la publicación, catalogándola como un acto de violación a la comunicación privada, y señalando que nada de lo propuesto se había aplicado. Sin embargo, el TSE señaló que el documento constituía una comunicación oficial de alcance público. Además, las evidencias de la aplicación de las estrategias del memorándum abundaban:

- El grueso del discurso de la campaña del "Sí" se había sustentado en el recurso al miedo, a perder empleos, a la vinculación del No con los movimientos Chavistas y con Cuba, al aislamiento y al atraso.

- Parte del discurso de los defensores del Tratado ya había aludido al supuesto carácter violento de los simpatizantes del "No": "Un núcleo fuerte de los opositores al Tratado de Libre Comercio son gente que combate nuestro sistema democrático, son anti-sistema", había expresado el entonces Presidente de la Asamblea y diputado del PLN, Francisco Antonio Pacheco (véase Ditsö y otros 2009).

- Al momento de la publicación del memorándum, el Gobierno ya había activado un proceso público de involucramiento de los 73 alcaldes y alcaldesas del PLN a la campaña del "Sí".

La publicación del memorándum no solo le costó su puesto a Casas y a Sánchez, sino que, lo más importante, desnudó el uso de recursos discursivos y mediáticos, así como acciones concretas desde el Gobierno y desde el sector empresarial que, en sí mismos, comportaban un claro mensaje simbólico: no importaba la discusión ni la argumentación racional, política, social, económica y técnicamente razonaba, solo correspondía promover el miedo. 


\section{El manejo informativo y la agenda mediática de los principales medios de difusión}

Tanto antes como a lo largo del proceso de referéndum, los principales medios de difusión no solo tomaron postura a favor del TLC, sino que, además, renegando de proponer una discusión y un debate asentados en el análisis racional y argumentativo, aplicaron de manera sistemática diversos recursos simbólicos para tratar de asegurar la legitimación social y la aprobación del Tratado. Al respecto, Cortés $(2009,65)$ señala:

El enfoque noticioso reforzó la campaña del Sí, incluyendo el énfasis en temas como el empleo (generación/perdida), el tratamiento al NO como movimiento violento, el supuesto vínculo del NO con gobiernos extranjeros (Ortega, Chávez y Fidel) y el aislamiento de Costa Rica si triunfaba el NO. El envoltorio noticioso daba a estos temas un mayor alcance, aunque también contribuyó a que muchos ciudadanos percibieran el enfoque parcializado que tienen la mayoría de estos medios comerciales.

A lo largo del proceso, los principales medios hicieron una sola voz en favor del TLC. La ya de por sí desproporcionada campaña publicitaria del "Sí" se nutría de un manejo informativo tendenciosamente favorable al TLC. En este manejo tendencioso destacaron algunos medios, entre ellos La Nación, Repretel y los medios públicos del Sistema Nacional de Radio y Televisión (Sinart). En estos casos, no solo se manejaba una línea editorial en claro favor del Sí, sino que, además, se priorizaban noticias y opiniones de actores políticos y del empresariado que exponían sus posiciones a favor del TLC.

Dado el peso simbólico que tuvo el manejo mediático, a continuación se presenta una serie de opiniones de algunos periodistas y figuras relacionadas con los medios, que vivieron de manera directa o indirecta los "avatares" de estos manejos mediáticos, todos ellos tomados del documental (Ditsö et al 2009):

Sufrimos esa presión y esa autocensura desde nosotros mismos. Cuando las rutinas informativas actúan, el periodista solo tiene dos posibilidades: o las sigue, o renuncia (Sylvia Carbonell, ex-subdirectora del noticiero Eco News, en Ditsö et al 2009). 
Durante 16 años de trabajar en el periódico La Nación, yo no recuerdo ningún otro período en donde haya habido una intervención tan evidente y burda de las posiciones editoriales de la empresa sobre la línea informativa del periódico (...). Existía una práctica de estar recibiendo recomendaciones directas desde Casa Presidencial o del Ministerio de Comercio Exterior acerca de temas y enfoques que se debían atender en torno a asuntos relacionados con el TLC (Mauricio Herrera, periodista de La Nación durante la cobertura informativa del referéndum, en Ditsö et al 2009).

Había presiones, era lógico. Presiones donde subrepticiamente le decían a uno que se estaban jugando la publicidad, no propiamente en el referéndum, sino la publicidad futura de empresas que se vinieran a establecer al país, empresas establecidas que estaban apoyando el TLC (William Gómez, Director del Diario Extra en la época del referéndum, en Ditsö et al 2009).

De parte del gran empresariado nacional, el cual evidentemente tiene acciones, intereses dentro del periódico La Nación, entre los grandes medios costarricenses, había sumas multimillonarias en juego, había cuotas para exportación de azúcar, nuevas condiciones para exportar atún (...). Con intereses tan grandes en juego, los dueños de los medios perdieron todo el pudor para influir en las líneas informativas de sus medios de comunicación, en aras de defender la aprobación del Tratado de Libre Comercio por los medios que fueran necesarios (Mauricio Herrera, periodista de La Nación durante la cobertura informativa del referéndum, en Ditsö et al 2009). 


\section{La violación a la tregua electoral}

El manejo mediático proclive al Sí se intensificó al final de la campaña, y, en particular, durante la semana previa al referéndum, llegando incluso a violentar la "tregua" electoral. Al decir de Cortés $(2009,68)$, "la campaña del Sí, en colusión con los medios, manipuló la libertad de prensa para desarrollar un bombardeo noticioso con una carga amarillista orientada a generar miedo para favorecer al Sí o paralizar a quienes simpatizaban con el No durante la tregua".

El ambiente se tensó aún más en la semana previa al referéndum, debido a una publicación de primera plana del periódico La Nación en la que se presentaba el resultado de una encuesta que colocaba al "No" arriba con una intención de voto del 55\%, respecto a un 43\% para el "Sí". En esa misma semana se hizo pública una nota enviada por el Gobierno de Estados Unidos al de Costa Rica, en la que se indicaba que, en caso de que el TLC no se ratificara, no habría ninguna posibilidad de re-negociación. La opción de re-negociar se había posicionado como un argumento del "No" para no apoyar el Tratado, pues implicaba una vía para saldar al menos algunos de sus contenidos más cuestionados. Por tanto, la carta supuso un golpe a este argumento del "No".

La nota fue aprovechada por las figuras del "Sí" para salir a fortalecer la campaña del miedo en los medios, y esto se dio incluso en momentos en que ya aplicaba la "veda" publicitaria establecida por el TSE. Este manejo de parte de los medios se dio a la par de la invisibilización y de la exclusión de los actores del "No", quienes, en lo fundamental, fueron ignorados o marginados de espacios equivalentes para referirse al asunto. La estocada de este "fraude mediático" se dio mediante la excepcional repetición, en diversos medios y a lo largo de todo el sábado previo al referéndum, de una entrevista realizada por el periodista Alberto Padilla, de la CNN, a un economista de la Universidad de Georgetown que llamaba a apoyar al TLC ante el supuesto de que no hacerlo implicaba que el país se quedaría solo en el mercado internacional (ver CNN 2007).

Según un estudio de Fournier y Cortés (2007), el manejo mediático de las informaciones difundidas en los medios durante los días de la veda condujo a un cambio en la intención de voto de un sector de la población, el cual terminó por marcar la diferencia a favor del "Sí": "hay una proporción muy importante de gente que había decidido votar por el "No" y que la última semana decide votar por el "Sí", y ese vuelco es claramente superior entre los que vieron el programa de CNN" (véase Ditsö y otros 2009).

\section{El papel del TSE}

Un apartado particular amerita el papel desempeñado por el TSE, al menos en dos aspectos particulares. Por un lado, en cuanto al aval que diera para que las autoridades del Poder Ejecutivo pudieran hacer proselitismo, con lo 
cual abonó al uso irregular de recursos públicos para favorecer a la campaña del "Sí". Esto se hizo contraviniendo el artículo 95 de la Constitución Política y el artículo 88 del Código Electoral (Cortés 2009), los cuales establecen la imparcialidad de las autoridades de gobierno. Por otro lado, y de manera contradictoria, el TSE prohibió a las universidades públicas que se involucraran en el proceso, cuando cumplían un importantísimo papel como generadoras de fundamentos y argumentos económicos y sociales para oponerse al TLC.

\section{La campaña del No}

Para finalizar, corresponde mencionar algunas de las particularidades del movimiento social que concretó la campaña del "No", no tanto porque abone al eje central del trabajo, sino por el significado histórico y social que tuvo. No hay duda de que, pese a no haber logrado el objetivo de frenar el TLC, este proceso es histórico para el movimiento social-popular en Costa Rica.

El esfuerzo colectivo de alcance nacional que caracterizó este movimiento no implicó el establecimiento de una estructura formal ni mucho menos jerárquica. Aunque existió una instancia de coordinación nacional, el proceso de toma de decisiones, intercambio, discusión e información que se puso en marcha respondió a una combinación de acciones programadas desde esa coordinación y una suerte de acciones espontáneas, tanto individuales como de organizaciones y colectivos independientes. El principal recurso motor que caracterizó este movimiento fue -más allá de retórica - el aporte individual y colectivo sustentado en la convicción compartida de que el TLC no debía aprobarse porque expresaba, en fondo y en forma, la sustancia de los peores elementos del sistema político y de la propuesta neoliberal. Como parte de este esfuerzo, se publicaron, compartieron y difundieron miles de materiales impresos, audios y materiales de video que se distribuían en discos de "DVD", comunidad por comunidad. Se realizaron foros, conversatorios y rutinas semanales de visitas casa por casa, con conversaciones que se sostenían cara a cara, directamente con la gente.

A pesar del antecedente del "Combo del ICE", y a pesar de haber cerrado el referéndum con una derrota en las urnas, podríamos afirmar que el movimiento social que se constituyó para impulsar la campaña del "No" ha sido la mayor expresión de movilización y organización social que ha tenido el movimiento social en Costa Rica desde la Guerra Civil del 48. 


\section{Los medios y los recursos simbólicos estratégicos operando en el presente}

Hasta acá se ha mostrado cómo, durante el proceso del referéndum, los medios en general reflejaron, de diversas formas tanto implícitas como explícitas, las posiciones del gran empresariado y del sector de la derecha política en favor del TLC. Es interés de este trabajo dejar evidencia de que este vínculo entre medios y sector empresarial no constituyó una situación casual. Dado que el planteamiento no se sustenta en una investigación formal, para tratar de mostrar que la aplicación de estos recursos de manejo o manipulación desde los medios se da de manera recurrente, acudiremos a la consignación de algunos casos concretos:

- La campaña del miedo contra José María Villalta en las elecciones presidenciales del 2014.

- El ocultamiento de la "Ley Participativa de Radio y Televisión" y las cuñas injuriosas de CANARA.

- El ocultamiento de las intervenciones de diputados del FA en la cobertura legislativa 2014-2018.

- La reunión entre dueños y directores de La Nación y Canal 7 con la cúpula de campaña del PLN.

\section{La campaña del miedo contra José María Villalta en las elecciones presidenciales del 2014}

Para la primera ronda de las elecciones presidenciales del 2014, realizada en febrero de ese año, en un contexto político en el que se ponía de manifiesto la crisis del bipartidismo tradicional y la tendencia de una parte importante de la ciudadanía a buscar otras opciones electorales, el candidato del partido Frente Amplio (FA), José María Villalta, con una propuesta de izquierda moderada, fue víctima del recurso político y mediático del miedo. En poco menos de un mes, Villalta sufrió un significativo desplome en la intención de voto que lo "sacó" de la segunda ronda, debido a la aplicación del recurso del miedo al "Chavismo" y a la izquierda por parte de los principales partidos contendores, cuyas manifestaciones fueron interesadamente acogidas desde las principales plataformas mediáticas.

En las semanas previas a las elecciones, el diario La Nación publicó los resultados de una encuesta en la que Villalta se ubicaba en el primer lugar de la intención de voto, la cual coincidía con otra que ese mismo diario publicara a inicios del mes de diciembre anterior.

Ya desde el mes de diciembre del 2013, cuando las encuestas ponían al FA en los primeros lugares, tanto los candidatos del "bipartidismo" tradicional 
como el sector empresarial y los medios - que hacían eco resonante de lo que aquellos manifestaban-, empezaron a trabajar en la difusión de mensajes en los que, sin más fundamento de fondo que su ideología y su interés electoral para descalificar, vinculaban al FA y a Villalta con Hugo Chávez y con Daniel Ortega. Un ejemplo de esto lo encontramos en la edición del periódico La Nación del 2 de diciembre del 2013, donde se publica una noticia con el título "Johnny Araya y Otto Guevara enfilan ataques contra José María Villalta", seguido de un cintillo que dice "Candidatos del PLN y Libertario acusan de peligroso al Frente Amplio". El texto de la nota expresa literalmente lo siguiente:

Johnny Araya y Otto Guevara, candidatos del PLN y del

Movimiento Libertario, dirigieron desde ayer sus baterías políticas contra José María Villalta, del Frente Amplio, tras conocer el resultado de la más reciente encuesta de Unimer para La Nación (...). Araya dijo que la propuesta de Villalta es un peligro para la democracia, mientras que Guevara lo calificó de "chavisandinista" (Oviedo y Agüero 2013).

El impacto de esta "campaña del miedo" fue contundente. Después de que la encuesta del 16 de enero colocara a Villalta en el primer lugar, los resultados de las elecciones lo dejaron en un tercer puesto, que no le alcanzó para llegar a segunda ronda. Los resultados finales de la primera ronda apenas dieron un $17,25 \%$ al FA, insuficiente para superar al PAC, con un $30,64 \%$ o al PLN, con un 29,71\%.

El recurso al miedo utilizado en esta campaña, conectado a las "emociones irracionales anticomunistas" —en virtud de que, a tono con los discursos políticos y mediáticos difundidos, se vinculaba al proyecto político del FA con el exgobernante venezolano Hugo Chávez, con el comunismo y con el "régimen" cubano-, tiene larga data en el escenario político-ideológico-electoral costarricense (Gamboa 2013). Se ha construido, reproducido y utilizado durante décadas. Ha sido utilizado de manera sistemática para tratar de deslegitimar múltiples luchas sociales, y fue también uno de los elementos de contenido al que más se recurrió como parte de la "estrategia del miedo" durante el proceso del TLC y el referéndum.

\section{El ocultamiento de la "Ley Participativa de Radio y Televisión" y las cuñas injuriosas de CANARA}


Un ejemplo evidente de la aplicación de los recursos del miedo, el ocultamiento y la exclusión de actores de parte de los grandes medios de alcance nacional lo ha vivido, desde el 2015, la "Red de Medios e Iniciativas de Comunicación Alternativa" (Red Mica), a propósito de sus esfuerzos por promover un debate sobre la democratización de los medios, y de la Radio y la Televisión, en particular.

La Red Mica es una organización sin fines de lucro que, desde el año 2009, al lado de otros actores académicos y sociales, viene impulsando un proceso de información y debate sobre este tema. Como parte de este proceso, el 14 de marzo del 2015 hizo pública la propuesta de proyecto de "Ley Participativa de Radio y Televisión". Entre otros principios, esta propuesta se fundamenta en el "Derecho a la Comunicación", el cual se nutre del derecho a la libertad de expresión y el derecho a la información, y plantea la necesidad de que la sociedad incorpore condiciones equitativas de acceso a los medios, en especial de aquellos que usan el espectro radioeléctrico (la radio y la televisión), dado que es un bien público, y dada la clara tendencia a su concentración.

La propuesta de Ley Participativa de Radio y Televisión se fundamenta también en principios de diversidad de actores y medios, y de pluralidad de voces. Además de establecer vías para el ordenamiento del espacio en el espectro y un cobro actualizado de los impuestos de uso del recurso, plantea el establecimiento de participación ciudadana en los órganos políticos que rigen el uso del espectro, así como el establecimiento de "reservas de espectro", las cuales permitirían disminuir el acaparamiento de parte de grupos empresariales, y asegurar espacio para medios públicos y medios comunitarios.

La emergencia de una propuesta de ley como esta generó malestar en los propietarios de los grandes medios, y en los grupos que representan públicamente sus intereses -en particular, la Cámara Nacional de Radio (CANARA) - , debido a que afecta de manera directa el privilegio del que gozan sus miembros mediante el aprovechamiento excluyente del recurso. La aplicación de los recursos de manipulación mediática respecto a esta propuesta ha sido clara:

- Se ha intentado desprestigiar a la Red Mica y al movimiento que ha generado a la luz del tema, calificándoseles de "usurpadores de la libertad de expresión" y "enemigos de la democracia".

- Se ha ignorado y ocultado por completo, ante la opinión pública, tanto el problema de acaparamiento de frecuencias como la existencia de la iniciativa de ley.

- Se ha excluido al colectivo de voceros de la organización de participar en los espacios informativos, o se ha negado la inclusión de sus versiones en las escasísimas noticias que circulan sobre el tema.

Dos ejemplos concretos expresan la forma en que ha operado la aplicación de estos recursos para el caso de la Red Mica: 
Primero: Con el fin de dar a conocer a la opinión pública la iniciativa de ley, la Red Mica convocó a una conferencia de prensa el 15 de marzo del 2015, en el auditorio del Colegio de Periodistas (véase Rojas 2015). Como era de esperar, la invitación convocó a muchos, incluyendo algunos de los grandes medios nacionales, y entre ellos a Noticias Repretel (de los canales 6 y 11), a Telenoticias (de Canal 7) y al Grupo Extra (que incluye al "Diario Extra" y al telenoticiero "Extra-Tv 42").

A pesar de estar presentes en la conferencia de prensa, ni Repretel ni Telenoticias hicieron publicaciones al respecto (iclaro!, hacerlo habría implicado colocar en la agenda pública un tema que para nada conviene a los grandes empresarios de los medios). El grupo Extra, por su parte, publicó una nota en la edición del telenoticiero del medio día, que se reflejó en la página web del grupo; sin embargo, la nota salió de circulación del noticiero y de sus redes sociales antes de que terminara la tarde.

Segundo: La Red Mica optó por presentar la propuesta de "Ley Participativa de Radio y Televisión" por la vía de una iniciativa popular, con el fin de contar con mayor legitimidad y no tener que lidiar con las barreras políticas que se dan habitualmente cuando las propuestas se presentan por medio de algún partido político. Para esto, debía recoger unas 150 mil firmas, el 5\% del padrón electoral, ya que es el requisito para que la propuesta pueda ser recibida en la Asamblea Legislativa.

Para el mes de julio del 2015, la Cámara Nacional de Radio (CANARA), que aglutina y defiende los intereses de una parte importante de los empresarios de los medios de radio del país, aprovechó su programa "Panorama" —que se emite de lunes a sábado durante las mañanas en las radio-emisoras de todos sus asociados - para difundir, durante las tres semanas previas a la romería, una serie de cuñas difamatorias contra la Red Mica. En estas cuñas, "alertaba" a "los romeros" sobre los que consideraba "enemigos de la libertad de expresión", previniéndoles para que estuvieran "alertas". El siguiente es el contenido de una de las cuñas difundidas en el programa Panorama:

Mientras muchos fieles se preparan para realizar la tradicional "romería", otros alistan sus discursos para sorprender a quienes se dirigen a la Basílica de Los Ángeles, en honor a "La Negrita". ¡Cuidado, romeros!, los enemigos de la libertad de expresión e información, le esperan para solicitarle una "firmita" para impulsar una nueva ley de radio y televisión, la cual solo perjuicios nos traería. Digamos no a quienes utilizan la sagrada tradición de la romería para impulsar sus ideas chavistas en materia de medios de comunicación, los cuales quieren poner al servi- 
cio del poder político y así acallar cualquier voz disidente.

Por eso, digamos no a los enemigos de la democracia

(CANARA 2015).

A raíz de la difusión de estas cuñas, la Red Mica presentó ante CANARA una solicitud de derecho de respuesta, la cual fue rechazada por los "defensores de la libertad de expresión y de la democracia" (ver Zúñiga 2015).

\section{El ocultamiento de las intervenciones de diputados del FA en la cobertura legislativa 2014-2018}

Otro ejemplo en el que se pone de manifiesto la forma en que se activan recursos de ocultamiento y exclusión, es el caso de la cobertura mediática de parte de los informativos de los grandes medios a los diputados y diputadas de la fracción legislativa del Frente Amplio (FA), durante sus intervenciones en el plenario o en comisiones, a lo largo de la gestión 2014-2018.

Dos periodistas vinculadas a la gestión de prensa de la fracción del FA durante el período indicado dieron cuenta de estas situaciones en varias comunicaciones personales. En conversación personal (29 de marzo 2018), Seidy Salas, quien trabajara en la Jefatura de Prensa del Frente Amplio en el período 2014-2017, comentó que era costumbre de los medios apagar las cámaras y los micrófonos, en particular en el trabajo de comisiones:

El periodista asignado por Repretel a la Asamblea Legislativa hacía las entrevistas de nuestros diputados y luego, a la hora de editar las noticias, los sacaba. Cuando le reclamábamos por qué, nos decía que sus jefes le pedían llevar cinco o seis diputados y luego escogían a tres, y obviamente los nuestros nunca salían... en la edición los terminaban recortando. Esto de apagar el micrófono lo veíamos también en las comisiones, con Telenoticias, con Repretel...

Por otro lado, Andrea Alvarado, quien fuera asesora de prensa del FA entre el 2016 y el 2018, también en conversación personal (29 de marzo 2018) manifestó que era común que los diputados y diputadas del partido no fueran incluidos en las noticias habituales sobre el acontecer legislativo: "los discursos de las y los diputados del FA casi nunca son usados o reproducidos por los 
periodistas". Es claro que estas estrategias de ocultamiento de las posiciones y discursos de los diputados y diputadas del Frente Amplio se aplicaban para evitar que tuvieran proyección pública.

\section{Reunión entre dueños y directores de La Nación y Canal 7 con la cúpula de campaña del PLN}

Finalmente, y a modo de cierre de este segmento, con el interés de refrescar un poco la memoria sobre uno de esos tantos hechos que aparecen en la agenda pública pero que suelen quedar en el olvido, dado el nada casual escaso tratamiento y seguimiento mediático, queremos recordar la polémica reunión que sostuvieron directores y dueños de La Nación y Canal 7 con la cúpula de la campaña del candidato Johnny Araya, el día anterior a que se hiciera público el retiro de este candidato de la segunda ronda de las elecciones del 2014.

En el mes de marzo del 2017, el Semanario Universidad dio a conocer una información en la que se daba cuenta de una reunión sostenida, en las previas al anuncio del retiro del PLN de la segunda ronda de las elecciones del 2014, entre el equipo de campaña de Araya y los periodistas Ignacio Santos y Armando González, directores de Telenoticias y La Nación, respectivamente, al lado de los dueños de esos medios, René Picado, de Canal 7, y Manuel Jiménez, de La Nación. Después de que se verificara la reunión por parte de los participantes, estos intentaron "aclarar" que la reunión solo perseguía objetivos informativos, y que se hacía en "consideración" del peso de ambos medios. Dado que este tipo de anuncios se hace en el marco de conferencias de prensa abiertas y públicas, desde una perspectiva periodística resulta poco creíble convocar a dueños y directores de medios con fines informativos. Por lo tanto, esta situación abonó de manera sustantiva a la idea de que las cúpulas de ciertos partidos políticos y los medios -en este caso, directores de informativos y dueños - mantienen vínculos muy cercanos y nada convenientes para el ejercicio informativo independiente.

\section{Estado, operadores privados y uso del espectro radioeléctrico en el contexto de la Tv Digital}

La privatización "de hecho" de la radio y la televisión en Costa Rica se explica, en parte, por la normativa vigente, que fue emitida en 1954, cuando ni siquiera existía en el país la radio FM, y mucho menos existía la televisión. Después de casi 70 años, lejos de ser ampliada y mejorada, esta ley solo ha sufrido modificaciones para derogar la mayoría de sus 27 artículos originales. Al carácter obsoleto de esta ley se suma una gestión negligente y omisa de parte del Estado, hecho señalado incluso por la propia Superintendencia de 
Telecomunicaciones (Lara, 2014), que raya en un "manejo" conveniente e interesado para beneficiar al sector del empresariado de los medios privados.

La Red Mica también experimentó este manejo interesado de parte del Estado en favor del empresariado de los medios. A propósito de la iniciativa de "Ley participativa de Radio y Tv", y como parte del trabajo de incidencia para tratar de llevar esta propuesta de ley como iniciativa popular, en el 2015 la Red presentó una solicitud de reunión con el presidente Luis Guillermo Solís para exponer el diagnóstico de la situación y los sustentos políticos, jurídicos y sociales de la propuesta de ley. Concluyó la administración Solís y nunca se dio respuesta alguna a esta petición. Mientras tanto, ha sido de dominio público la realización de al menos un encuentro entre el Presidente y el Viceministro de Telecomunicaciones, Edwin Estrada, con representantes de diferentes cámaras de empresarios de medios.

Uno de los corolarios de esta relación entre la administración Solís y los empresarios de los medios ha sido, sin duda, la formulación del "Plan Nacional de Desarrollo de las Telecomunicaciones 2015-2021", dentro del cual se incluyó la denominada "Hoja de Ruta hacia la Televisión Digital Abierta". Esta ruta estableció el "camino" para concretar el cambio de la tecnología analógica -actualmente en uso para la transmisión y recepción de las señales de televisión abierta-, a la tecnología digital. Este cambio tecnológico comporta una "optimización" del espectro radioeléctrico, gracias a lo cual, en el mismo espacio en que se transmite una sola señal de televisión con la tecnología vigente, se podrían transmitir hasta 4 señales diferentes en tecnología digital. Esto significa que, donde hoy día hay un solo canal, se podrían tener hasta 4 canales (dependiendo de las calidades y características de las señales).

A pesar de que este "dividendo" es patrimonio público (pues implica una optimización del espectro, que es un bien demanial), la "hoja" de ruta definida por el gobierno concede a estos empresarios todo el dividendo digital de Tv, en correspondencia con las concesiones que tengan en el modo analógico actual. Así, por ejemplo, en el caso de Repretel, que en la tecnología analógica dispone de 4 canales en la banda de VHF, a partir del cambio a la tecnología digital se le concesionarían 16 frecuencias, las 4 actuales y 3 "multiplexores" (espacios adicionales) por cada una.

Esta verdadera piñata del patrimonio público se da a pesar de que se conocen experiencias en otros países, como México, Argentina, Alemania o Inglaterra, donde el cambio a la tecnología digital llevó al Estado a tomar el dividendo adicional y distribuirlo de acuerdo con criterios de interés público.

El cambio tecnológico quedó programado para el 19 de agosto del 2019, a pesar de que estaba originalmente previsto para el 15 de diciembre del 2017. El cambio de fecha se dio ante la escasa información pública sobre el proceso por parte del Viceministerio de Telecomunicaciones, y ante una solicitud del TSE, ya que implicaba dejar fuera de funcionamiento los televisores en uso (los que captan señales que circulan por el aire), con el fin de "resguardar el derecho al sufragio informado" (Ruiz 2017), ya que implicaría un riesgo 
para el debido proceso informativo, ante la cercanía del proceso electoral de febrero 2018.

Con el fin de tratar de frenar esta vía establecida por el Estado para concretar la digitalización, en julio del 2017 se presentó al público y se sometió a la Asamblea Legislativa una propuesta de ley, denominada "Ley sobre uso eficiente del espectro radioeléctrico en radiodifusión sonora y televisiva", la cual apunta a regular el proceso de digitalización de la Tv y a obligar al Estado a asumir la responsabilidad de gestionar este proceso con criterio social, de manera que, antes de entregarle el dividendo a los empresarios de los medios, se recupere este recurso y su uso se someta a procedimientos transparentes de asignación. Al momento de completarse este texto, el proyecto de ley estaba por completar su trámite en comisión.

\section{Reflexiones finales}

Lo ocurrido durante el referéndum por el TLC puso en evidencia un sistema mediático costarricense que es, de manera casi exclusiva, privado-comercial, y que —dada la acción por omisión-, bajo el amparo del Estado, se puso "al servicio" de los intereses empresariales que le son consustanciales. Al respecto, es importante entender que eso sigue siendo así: "los sistemas privados de control de los medios son una amenaza al espacio público por distintas razones (...). La sujeción al propietario y al anunciante hace que los medios caigan en una situación de doble favoritismo que amenaza el espacio público: tienden a ser políticamente conservadores y hostiles a la crítica de un "status quo" en el que son los mayores beneficiarios" (Herman y McChesney $(1999,19)$.

Por alguna razón, apelando a una cercanía simbólica poco tangible, a los medios e informativos les encanta atribuirse la potestad de representar y hablar por la gente, y de "estar a su lado". "El canal del pueblo" (Tv Extra 42), "siempre con usted" (Canal 7), "la radio de Costa Rica" (Monumental), "Nuestra Voz" (Amelia Rueda), son algunos de los lemas que acompañan las presentaciones diarias de varios de los medios y programas de mayor audiencia. Sin embargo, las experiencias concretas muestran que esas retóricas de cercanía con el pueblo distan de ser reales y que, en general, para los grandes medios, antes que sujetos activos con derecho pleno para tener presencia independiente, las personas son vistas como objetos de uso a partir de criterios editoriales basados en intereses comerciales y político-ideológicos particulares de los medios.

La experiencia del proceso de referéndum, así como las evidencias del presente reciente acá reseñadas, que constituyen solo algunos, entre muchos otros ejemplos posibles de reconstruirse entre múltiples experiencias de quien escribe y de tantos otros activistas sociales, da pie para hacer una afirmación que puede lucir atrevida, pero que es tajante y plenamente verifica- 
ble: lejos de ser pilares de la libertad de expresión, que es como se presentan ante la opinión pública, los medios privados-comerciales, que funcionan como empresas y cuya razón esencial es el lucro, son las entidades que más violentan la libertad de expresión en Costa Rica. La aplicación sistemática de contenidos y criterios editoriales-informativos basados en los recursos del miedo, del ocultamiento y de la exclusión, no son más que afrentas concretas a este derecho fundamental, el cual es, a su vez, soporte básico del sistema democrático.

El equilibrio mediático es indispensable en una sociedad que aspire a ser plenamente democrática. La vigencia del derecho a la libertad de expresión y la aspiración a una democracia plena precisan de dicho equilibrio, y eso implica asegurar la presencia de medios con criterios editoriales pluralistas, que expresen perspectivas y visiones diversas, en correspondencia con los múltiples grupos, sectores y posiciones político-ideológicas que conforman el entramado social. El Estado debe ser garante de esta pluralidad y, en el caso de la radio y la televisión, que utilizan el espectro radioeléctrico, que es un recurso público, la asignación de frecuencias debe expresar la diversidad que es consustancial a la realidad social, cultural y política del país, tal y como lo plantea la $\mathrm{CIDH}$ : "la asignación de licencias de radio y televisión debe estar orientada por criterios democráticos y procedimientos preestablecidos, públicos y transparentes, que sirvan de freno a la posible arbitrariedad del Estado ( $y$ del sector privado) y que garanticen condiciones de igualdad de oportunidades para todas las personas y sectores interesados" (CIDH 2010, 17; el texto en cursiva es un agregado nuestro).

Los medios comunitarios son fundamentales para lograr un modelo mediático realmente equilibrado. Ante un panorama de prevalencia de medios privadoscomerciales, constituyen la única vía para establecer el contrapeso necesario y para asegurar la existencia de referentes simbólicos alternativos al pensamiento y al mensaje política, económica e ideológicamente uniformado desde los medios empresariales-comerciales privados. Lo que pasó durante el proceso del TLC y el referéndum no es más que la confirmación de esta afirmación.

Si la democracia costarricense aspira a ser integral y plena, requiere romper la privatización "de hecho" que caracteriza el sistema mediático, en particular el uso del espectro radioeléctrico, y la única forma de asegurar esto es la promoción y apertura de medios ciudadanos-comunitarios que, por un lado, canalicen la voz de los diversos sectores y actores sociales organizados, especialmente de aquellos que no persiguen fines de lucro, y por otro, permitan a la sociedad tener acceso a otros referentes simbólicos -ideológicos y políticos- alternativos. 


\section{Bibliografía}

Amador, Marvin. 2003. Análisis de contenido de los noticieros Repretel y Telenoticias (inédito). San José: Maestría en Tecnología Educativa con énfasis en Medios Instruccionales, Universidad Estatal a Distancia (UNED).

CANARA. Digamos no a los enemigos de la democracia. Panorama, emitido en julio 2015, cuña para radio (0:50). https://leyderadioytele.wordpress.com/2015/07/27/audio-campana-decanara-utiliza-argumentos-falsos-y-sin-fundamento/

Casas, Kevin y Fernando Sánchez. 2007. Algunas acciones urgentes para activar la campaña del "SÍ" al TLC: Memorándum de Kevin Casas y Fernando Sánchez para Presidente y Ministro de la Presidencia de Costa Rica, 20 de julio del 2007. San José: Vicepresidencia de la República. Edición en pdf.

CIDH. 2010. Estándares de Libertad de Expresión para una Radiodifusión Libre e Incluyente. Organización de Estados Americanos: Relatoría Especial para la Libertad de Expresión de la Comisión Interamericana de Derechos Humanos. Edición en pdf.

CIEP. 2017. Informe de resultados de la encuesta de opinión sociopolítica realizada en noviembre de 2016. San José: Proyecto Estudios de Opinión Pública, Centro de Investigación y Estudios Políticos, Escuela de Ciencias políticas, Semanario Universidad. Edición en pdf.

CNN. Referéndum en Costa Rica. CNN, 6 de octubre 2007, video en YouTube (4:55). https://www.youtube.com/watch?v=n2_AVPFzXCs

Cortés, Alberto. 2009. Coyuntura y Política en Costa Rica (1998---2008): Artículos académicos, ensayos analíticos y artículos de opinión. San José: CIEP, Escuela de Ciencias Políticas, Universidad de Costa Rica. Edición en pdf.

Ditsö Grito de los Excluidos, Alexander Rojas, Paulo Cárdenas. Santo Fraude. Video en YouTube, enero del 2010. (1:23:30). https://www.youtube.com/watch?v=ZIT-r9C_H2I

Ducca, Isabel. El financiamiento del equipo negociador del TLC. Diario electrónico El País (2 de octubre 2017). https://www.elpais.cr/2017/10/02/ el-financiamiento-del-equipo-negociador-del-tlc/

Fournier, Marco y Alberto Cortés. 2007. Encuesta post-Referéndum (inédito). San José: Centro de Estudios Políticos de la UCR, Escuela de Ciencias Políticas, Universidad de Costa Rica.

Fuentes, Verushka. 2015. El componente ideológico-discursivo en la estructura de los actos y hechos sociales. Investigación y desarrollo 23 (1): 199-228. 
Gamboa, Manuel. 2013. «El anticomunismo en CR y su uso como herramienta política». Anuario de Estudios Centroamericanos 39: 143165.

González, Jaime. 1988. Comunicación Social y Dominación Ideológica. Heredia: EUNA, 1988.

Guinsberg, Enrique. 1988. Control de los medios, control del hombre. Universidad Autónoma Metropolitana, Unidad Xochimilco. México DF: Pangea Editores, 1988

Herman, Edward y Robert McChesney. 1999. Los medios globales: Ios nuevos misioneros del capitalismo corporativo. Madrid: Ediciones Cátedra S.A., 1999.

ICER. sf. Reglamento para el funcionamiento de las pequeñas emisoras culturales filiales del ICER, creadas por la ley 7299. San José: Instituto Costarricense de Enseñanza Radiofónica, Radio Cultural la Voz de Talamanca.

Jiménez, Oscar. 2017. La concentración en los medios de comunicación de Costa Rica: el caso de la radio y la televisión abierta. Tesis sometida a consideración de la Comisión del Programa de Estudios de Posgrado en Comunicación para optar al grado y título de Maestría Académica en Comunicación. Maestría en Comunicación y Desarrollo, Universidad de Costa Rica.

Lara, Juan. Sutel reitera grave subutilización de frecuencias de radio y televisión en Costa Rica. La Nación (5 de noviembre 2014). https://www.nacion.com/tecnologia/sutel-reitera-grave-subutilizacion-defrecuencias-de-radio-y-television-en-costa-rica/ QMGEA7FJWRFG3DQCLNRO4KGXMI/story/

OBSERVACOM. 2017. Libertad a medias: La regulación de los medios comunitarios en América Latina y su compatibilidad con los estándares interamericanos de libertad de expresión. Informe de medios Comunitarios y Libertad de Expresión. Observatorio Latinoamericano de Regulación, Medios y Convergencia, 2017. Edición en pdf.

Oviedo, Esteban y Mercedes Agüero. Johnny Araya y Otto Guevara enfilan ataques contra José María Villalta. La Nación (2 de diciembre 2013). https://www.nacion.com/el-pais/politica/johnny-araya-y-otto-guevaraenfilan-ataques-contra-jose-maria-villalta/ S6EDDK7N4ZBRTIP47TNTGQD2CY/story/

PROLEDI y CICOM. 2018. Primer informe del Estado de la Libertad de Expresión en Costa Rica. San José: Programa de Libertad de Expresión, Derecho a la Información y Opinión Pública, Centro de Investigación en Comunicación (CICOM), 2018.

Ramos, Celina. 1995. «Los medios de comunicación, agentes constructores de lo real.» Revista Comunicar 5: 108-112. 
Raventós, Ciska. 2008. «Balance del referendo sobre el TLC en Costa Rica a la luz de la teoría de la democracia». Revista de Ciencias Sociales 121: 13-29.

Rojas, Karen. 2015. Red MICA presenta ley participativa de Radio y Televisión. El Sol de Occidente (14 de marzo 2015). http://elsoldeoccidente.com/enlinea/2015/03/red-mica-presenta-leyparticipativa-de-radio-y-television/

Ruiz, Gerardo. Campaña política podría postergar el cambio de televisión analógica a digital. La Nación (11 de setiembre 2017). https://www.nacion.com/el-pais/politica/campana-politica-podriapostergar-el-cambio-de-television-analogica-a-digital/ JEHCVWBM25BO5KWG4A2IHXU77Q/storyl

Valderrama, Jairo. 2005. «La información, aprisionada por el poder y el espectáculo». Revista Comunicación 14 (002): 53-62.

Vargas, Jorge. 2008. «Costa Rica: una decisión estratégica en tiempos inciertos». Revista de Ciencia Política 28(1): 147-169.

Voorend, Koen y Francisco Robles. 2012. «Los dueños de la palabra en Costa Rica en un contexto de reforma neoliberal». Revista Rupturas 1(2): 144-161.

Zúñiga, Daniela. Virulento ataque de CANARA contra Ley Participativa de radio y Tv. Primera Plana (miércoles 29 de julio 2015). http://www.primeraplana.or.cr/es/El_Pa\%C3\%ADs/Virulento_ataque_de _Canara_contra_Ley_Participativa_de_Radio_y_TVI 